Psychological Medicine, 1985, 15, 227-236

Printed in Great Britain

EDITORIAL

\title{
Depression and dementia: the multi-faceted relationship ${ }^{1}$
}

The relationship between depression and dementia has been noted since antiquity and still eludes our precise understanding. Rosen (1961) notes that in the ninth century A.D. Rhazes, the Persian physician, mentions melancholy as an inevitable condition in the lives of old and decrepit persons. Later, both Robert Burton (Anatomy of Melancholy) and William Shakespeare, among others, commented on the association between cognitive and affective change.

It is now established that cognitive change is part of the symptomatology of primary depressive illness and it is, of course, the cardinal feature of the syndrome of dementia. Depressive illness is found predominantly as a condition of the middle-aged and the elderly; $90 \%$ of the dementias are found in the senium, i.e. beyond the age of 65 . Hence, an association at the very least between depression and dementia is to be expected. As both depression and dementia are heterogeneous collections of conditions, the precise relationship will, not surprisingly, be a complex one. Furthermore, depressive illness is still classified among the 'functional' psychiatric disorders, i.e. among those conditions which do not have a tangible organic causation, a state of affairs accepted despite its unsatisfactory nature. Evidence is accumulating that a substantial and growing proportion of depressive illnesses have neurobiological correlates and, as techniques advance, the position of some forms, at least, of depressive illness among the 'functional' disorders may become an untenable one. The converse applies to dementia. Very early the dementias became equated with 'organic' illness. But as knowledge has grown and our conceptualization of dementia has changed, we are now prepared to accept that the dementia syndrome may have 'organic' as well as 'functional' causation. A recent paper on dementia caused by depression (Rabins et al. 1984) emphasizes this point.

Dementia is nowadays defined as an acquired, global condition, with intellectual deterioration, memory impairment and personality disorganization in the presence of unimpaired consciousness (e.g. Lishman, 1978). As depressive illness is acquired, global in its manifestation and occurs in the presence of unimpaired consciousness, it is not difficult to see that any cognitive change in depressive illness, if it progresses to substantial deficits in intellectual, memory or personality functioning, will satisfy the criteria for the syndrome of dementia.

\section{CONCEPT OF 'PSEUDODEMENTIA'}

There is therefore a prima facie case for depressive illness leading to one form of dementia. It was in the context of studying groups of patients with apparent dementia, with observable depression and a course dissimilar to that of the majority of demented patients with progressive and terminal illnesses, that the concept of 'pseudodementia' originated. Post (1962) has referred to Gaupp's (1905) and Lange's (1928) descriptions of mild senile mental changes first emerging during affective illness and then disappearing on recovery from depression. Madden et al. (1952) found that 'symptoms ordinarily considered to indicate dementia (disorientation, defects in recent memory, retention, calculation and judgement)... may disappear on alleviation of the psychotic picture by means of short-term intensive therapy'. They applied the term 'pseudodementia' to those cases, who constituted $10 \%$ of their 300 cases of non-dementing psychoses.

The concept of 'pseudodementia' was thus based on three elements:

- Address for correspondence: Dr B. Mahendra, St Lawrence's Hospital, Bodmin, Cornwall PL31 2QT. 
(1) The syndrome of dementia in patients with 'pseudodementia' did not progress but was reversed in relation to the clinical state of 'functional' psychiatric illness.

(2) The cause of the dementia was the 'functional' psychiatric illness.

(3) Distinctions could be drawn between 'pseudodementia' conceptualized in terms of reversibility, lack of progression and of 'functional' causation and the 'true' dementias which were progressive, irreversible and had as their cause degenerative brain disease. This distinction was based essentially on clinical grounds but, to a lesser extent, psychological, radiological and other laboratory investigations were also used to distinguish between the two groups.

It was on this basis that Kiloh (1961) reported on 10 cases of 'pseudodementia' which he had studied. When he reported his findings, a standard British psychiatric text (Mayer Gross et al. 1960), in its second edition, described dementia as a progressive, irreversible and untreatable condition. Subsequent clinical studies (Marsden \& Harrison, 1972; Nott \& Fleminger, 1975; Ron et al. 1979; Wells, 1979; Smith \& Kiloh, 1981; McAllister, 1983) continued to use this conceptualization of ' pseudodementia'. These studies were reported in a critical spirit, the chief purpose usually being to draw attention to cases which, though demented at the time of presentation or examination, did not sustain their dementia, or even the cognitive disturbance in some cases, on follow-up. If dementia was considered a progressive, irreversible condition of organic aetiology, these patients could not be deemed to be demented; hence they were cases of 'pseudodementia'.

A salutary effect of these studies was to impress upon the clinician that cases of apparent dementia were not necessarily progressive, untreatable and irreversible but were, in substantial numbers, amenable to productive investigation and effective treatment. The causes of these dementias were predominantly forms of depressive illness, but among other conditions noted were: paraphrenia, mania and hysteria (Kiloh, 1961); mania, hysteria and drug toxicity (Marsden \& Harrison, 1972); shoplifting, bizarre hypochondriasis and persistent pain (Nott \& Fleminger, 1975); conversion and dissociative reactions, other neurotic conditions and schizophreniform conditions (Wells, 1979); and schizophrenia, mania and thyrotoxicosis (Smith \& Kiloh, 1981).

\section{2. 'TRUE' AND 'PSEUDO' DEMENTIA: CLINICAL DISTINCTION}

The clinical basis for distinguishing between 'pseudo' and 'true' dementia at the time of presentation was a subject discussed at length by Wells (1979). He drew up 22 points of distinction, including such features as: the onset of 'pseudodementia' could be dated with some precision; the symptoms in that state were of short duration and rapid progression; there was a history of antecedent psychiatric dysfunction; there was much complaint of cognitive loss and emphasis on disability; the patient communicated a strong sense of distress; there was pervasive affective change; 'don't know' answers were typical; memory loss for recent and remote events was equally severe; memory gaps for specific periods and events were common; and there was marked variability in performance on tasks of similar difficulty. On each of these points the patient with 'true' dementia was said to differ in a significant way which aided the differential diagnosis.

\section{3. 'TRUE' AND 'PSEUDO' DEMENTIA: PSYCHOLOGICAL DIFFERENCES}

In terms of the psychological distinction between 'pseudo' and 'true' dementia, the considerable variability of behaviour of the former, differences on detailed testing of memory function and the absence of focal or cortical deficits in the 'pseudodementia' group were stressed. Nott \& Fleminger (1975) noted that only their true demented patients showed problems with naming, writing, calculation or motor praxis. Ron et al. (1979) noted that, while overall intellectual impairment was present in 'pseudodements', they did not show a significant difference in verbal-performance IQ on the Wechsler Scale, whereas 'demented' patients showed a large discrepancy. Caine (1981), studying 17 patients with depressive cognitive disorders, found that specific functions such as repetition, reading and comprehension, naming, verbal delayed recall and recognition, mathematics, finger tapping and motor praxis were spared. Most impaired were tasks dependent on attention, 
mental processing speed, spontaneous elaboration and analysis of detail. Taken together, Caine believes that these findings are consistent with a picture of impairment in which cortically mediated intellectual functions are spared in 'pseudodements'. Recent work by Gibson (1981) and Weingartner et al. (1982) has thrown more light on differences in memory impairment in depressives and dements. It is suggested that in depression there is probably a suppression of otherwise normal memory processes, failures in learning being a function of the intensity of the depression, especially when random or unrelated events are being recalled. Their memory failures are most apparent on tasks that require sustained motivation, effort and active processing operations. In dementia, on the other hand, there is a more fundamental breakdown in the process of memory. Patients are unable to use relational properties to learn and remember information; they show difficulties in 'finding' what they have learned, including words; and they fail despite sustained efforts, even on tasks that would normally require little cognitive effort.

\section{4. 'TRUE' AND 'PSEUDO' DEMENTIA: DIFFERENCES ON PHYSICAL INVESTIGATION}

In terms of radiology, the air encephalogram (AEG) was studied in earlier attempts to make the distinction between 'true' and 'pseudo' dementia. Nott \& Fleminger (1975) noted that the gross widening of the ventricles occurred only in 'true' dementia, though nearly half of their 'pseudodements' were reported as having minimal sulcal or ventricular enlargement on the AEG. Ron et al. (1979) also found the AEG of value, though they noted that 'the high incidence of abnormalities in the non-demented group should not be overlooked. Most occurred in patients with established or suspected brain disorder and had then lent spurious support to the clinical impression that a progressive dementing illness was afoot'. Unlike Nott \& Fleminger (1975), Ron et al. (1979) concluded that cortical atrophy on the AEG appeared to be a better predictor of dementia than ventricular enlargement in their patients.

The advent of computerized tomography (CT) has helped to circumvent the technical and ethical problems associated with the AEG. As Jacoby (1981) has noted, the clinical introduction of CT was followed by enthusiastic statements with regard to its value in the diagnosis of dementia. Very soon it became clear that dementia can occur without atrophy and atrophy without dementia; the overlap can be substantial. Jacoby has also noted that a subgroup of elderly patients may show enlarged ventricles with significant mortality over two years' follow-up compared with depressives with normal ventricles, which might indicate an organic basis for some depressions of old age. Be that as it may, Wells (1979) did not find CT appearances, largely showing mild atrophy and minimal enlargement of the ventricles, useful in his study of 'pseudodements'. A more refined measure on CT is attenuation of radiodensity. Jacoby et al. (1983) studied brain tissue density by CT scans on depressed and senile dementia patients and control subjects. The depressed patients resembled the dements more than they did the controls. Also, ventricular dilatation in depressed patients - related in an earlier study to increased mortality - was found to be associated with lower values of brain tissue radiodensity.

Nott \& Fleminger (1975) found that the EEG failed to discriminate between patients with progressive dementia and those with non-progressive or reversible dementias. A striking feature was the $62 \%$ level of abnormality on the EEGs in their non-progressive group, not very significantly different from the $75 \%$ EEG abnormality in the progressive demented group. Ron et al. (1979), however, found that an abnormal EEG was significantly commoner in their demented group, the most frequent abnormality reported being the presence of symmetrical intermediate or slow activity.

Neuroendocrinological studies have been evoked in recent years to make the distinction between dementia and depression. A non-suppressive (i.e. abnormal) response to the dexamethasone suppression test (DST) helped to diagnose, it was alleged, primary 'endogenous' depression with high specificity (Carroll et al. 1976, 1981). Rudorfer \& Clayton (1981), among others, claimed that the DST was useful in distinguishing organic and affective symptoms, but a growing number of reports, including one by Spar \& Gerner (1982) who found abnormal DST results in 9 of 17 elderly 
patients with dementia but without major depressive illness, have cast doubt on earlier, enthusiastic claims, and the situation now remains more equivocal. The abnormal DST in dementia will be referred to later in the discussion on Alzheimer's disease.

\section{CHANGING CONCEPTS OF DEMENTIA}

While these attempts were being made to distinguish 'true' from 'pseudo' dementia, in the past ten years two important developments have resulted in the conceptualization of dementia being altered in quite fundamental ways. First, the requirement for an irreversible, progressive course for dementia, and with it the inevitable criterion of organic causation for the syndrome, ceased to exist. Three definitions of dementia which have become influential are those by Marsden \& Harrison (1972), Lishman (1978) and the Report of the Royal College of Physicians (1981). They have defined dementia in terms of an acquired, global defect of intellect, memory and personality in the presence of unimpaired consciousness. Progression and irreversibility are no longer conditions that require to be satisfied for the diagnosis of dementia; neither is there consideration of any aetiological factors in the diagnosis. Dementia may result from gross organic disease; it can progress to a fatal termination with no question of reversal. On the other hand, dementia, even perhaps as serious a clinical entity as an organically-determined dementia, may reverse and subside with the effective resolution of the 'functional' psychiatric illness responsible for it. Both states are dementias because they both satisfy the criteria for the diagnosis of dementia - progression, irreversibility and aetiology being now irrelevant factors. It has therefore been argued that the concept of 'pseudodementia' is no longer sustainable on logical grounds (Mahendra, 1983).

The second new factor in the modified conceptualization of dementia is that the tacit assumption that dementia is a cortical phenomenon can no longer be held to be a central, or even essential, feature of the syndrome. It is now suggested that a category of 'subcortical' dementia exists. Albert et al. (1974) and Albert (1978) have suggested that the following are features of 'subcortical' dementia:

(1) emotional or personality changes (typically inertia or apathy, occasionally with outbursts of anger);

(2) memory disorder;

(3) defective ability to manipulate acquired knowledge;

(4) striking slowness in the rate of information processing.

The subcortical dementias are distinguished clinically from the 'cortical' dementias by the preserved vocabulary and facility with language in the former. No aphasias, agnosias or apraxias are seen in them, unlike the 'cortical' dementias. Thus the cognitive changes occasionally to be found in such conditions as Parkinson's disease, Huntington's chorea, progressive supranuclear palsy and Korsakoff's syndrome could be brought under the rubric of dementia. Moreover, growing evidence points to the heterogeneity of Alzheimer's disease. A substantial number of patients with this condition do not have cortical features in the early stages of the disease. The Alzheimer disease patient who has early cortical features is also likely to have the severe, rapidly progressing form of the illness; often he or she is the younger, pre-senile patient, with a family history of the illness, sometimes displaying other neurological features and dying sooner than the older, senile patient with a slower-progressing, sporadically contracted Alzheimer's disease (Sourander \& Sjogren, 1970; Seltzer \& Sherwin, 1983).

The point about this digression on the conceptualization of 'subcortical' dementia is that it serves as another basis for reconsidering the distinctions between 'pseudodementia' (often, as we have seen, of depressive origin) and the 'true' dementias. We have noted in previous paragraphs that the distinction between these was upheld on the grounds that relatively small cerebral changes, or none at all, were found in depressive 'pseudodementia' and rather gross changes in 'true' dementia. With the arrival of the 'subcortical' dementias, this distinction becomes blurred. Depressive and other 'pseudodementias' are distinguished by the lack of cortical features; but so are the subcortical dementias. Caine (1981) has shown that psychological testing in 'pseudodementia' reveals a subcortical pattern of cognitive deficit. Recently, Mayeux et al. (1983) studied demented 
patients with Alzheimer's disease, Parkinson's disease and Huntington's chorea. Alzheimer's disease was diagnosed clinically, using rigorous criteria which excluded focal features, i.e. the more severe forms of the illness were likely to have been eliminated. The result was that more than half the Alzheimer's disease patients in that series showed mild/moderate impairment on clinical assessment, and no distinctive pattern of neuropsychological impairment could be shown between the cases of Alzheimer's disease, Huntington's chorea and Parkinson's disease.

Thus the concept of 'pseudodementia' which might have served a purpose for some decades appears to be no longer tenable as a result of two major advances in the conceptualization of dementia in the past decade. Dementia now is a descriptive term, without qualification as regards progression or irreversibility and without aetiological connotation. Dementia also subsumes conditions with and without cortical features, and 'subcortical' dementia shares many features in common with depressive, and other, 'pseudodementia'. As such, the distinction between 'pseudo' and 'true' dementia no longer possesses the sharpness or clinical utility which it once might have had. As a parallel development, we now also have a growing number of what once might have been called 'true' dementias that have turned out to be reversible - for example, normal pressure hydrocephalus, the metabolic dementias. Like them, depressive dementia should now be considered within the category of reversible or treatable or secondary dementias, and as a form of 'subcortical' dementia.

\section{DEPRESSION IN DEMENTIA}

It is known, of course, that depression is a pervasive symptom, no less so in neurology than in psychiatry. The true incidence of depression in Alzheimer's disease or in conditions such as Parkinson's disease or Huntington's chorea is not known for certain, but it has been suggested (Kral, 1983) that depression might have been present in $15 \%$ of patients in a series in which Alzheimer's disease was clinically diagnosed. Depression is known to be a symptom of the early stages of the disease (Roth, 1978). It may be fleeting and not well differentiated. Response to treatment of the depression may be poor, but the depressive features disappear as the Alzheimer's disease progresses, and may not be seen in the severe form of the illness even in the early stages. Thus, when rigorous research clinical criteria are employed to obtain a diagnosis of Alzheimer's disease - presumably to make certain the cases were indeed of Alzheimer's disease, a course of action that favours the inclusion of more severe cases - there was no depression in 30 cases of dementia (Knesevich $e t$ al. 1983).

Kral (1983) has considered the significance of depression in Alzheimer's disease. There cannot be any certainty on this point, but it would appear that depression does not carry any prognostic implications and the treatment of the depression by antidepressant drugs with anticholinergic properties does not alter the natural history of Alzheimer's disease. Kral (1983) also took the opportunity of studying 22 'pseudodements' on follow-up and found that 20 of them had developed progressive dementia, the clinical appearances being that of Alzheimer's disease, and that 11 of these had died. Histological confirmation was available in three of these patients. These are surprisingly large numbers of patients with Alzheimer's disease presenting with depression. The follow-up, however, was for a mean of 8 years, which is beyond the 2-5 year range of survival usually expected in Alzheimer's disease. A further line of inquiry throws some light on this intriguing state of affairs. It has already been mentioned that recent reports have suggested that demented patients could show abnormal suppression on the Dexamethasone Suppression Test (DST). Mahendra (1984) has suggested that it is the slower progressing form of Alzheimer's disease that shows this abnormality, which gives it a point of affinity with a certain type of depressive illness. A possible explanation is that the normal DST is a reflection of the integrity of the hypothalamo-hypophyseal-adrenal axis, which is mediated by cholinergically active neurones. Carroll et al. (1978) have suggested that the abnormal DST in cases of depression may be due to hyperactivity in the muscarinic cholinergic transmitter system. In slowly progressing Alzheimer's disease there is presumably a relatively high cholinergic activity which gives rise to the abnormal DST. As the disease progresses with diminution of cholinergic activity, there is correspondingly less scope for an abnormal DST. This relatively 
normal or high cholinergic activity may be one possible reason for the predisposition to depressive symptoms in the early stages of Alzheimer's disease.

Depression and dementia are also features of Parkinson's disease and Huntington's chorea. Mindham (1970) showed that $90 \%$ of cases with Parkinson's disease displayed depressive features, a figure now conceded to be an exaggeration but suggesting the association with depression to be beyond dispute. Impairment of intellectual function amounting to dementia has been found in $20-40 \%$ of patients with Parkinson's disease (Mindham et al. 1982). It has been shown that this is not merely a reaction to disability, and it has also been suggested that no relationship exists between the degree of depression in parkinsonian patients and either the duration of the disease or the severity of the physical disability (Celesia \& Wanamaker, 1972; Robins, 1976). There appears to be some relationship between the purely neurological features of parkinsonism, the depression and the dementia, but its exact nature is as yet uncertain. There is the further complication that the depression often runs an independent course from the rest of the clinical features. Robins (1976) tried to discuss the parkinsonism and depression in terms of a common monoamine deficiency, but the lack of any consistency forced him to concede the possible existence of a more complex biological relationship than he had envisaged.

Dementia, on the other hand, is known to be a late feature of Parkinson's disease. Marsden (1982) has noted that dementia develops in about a third of patients in the later stages of Parkinson's disease, the commonest form pathologically being Alzheimer's disease. Perry et al. (1983) have disputed this and referred to lowered cholinergic activity in such patients who do not, however, show the classical histopathological features of Alzheimer's disease. As long as Alzheimer's disease is defined in histopathological terms, we are prisoners of that particular concept but, in view of what has been suggested as regards the heterogeneity of Alzheimer's disease, there is growing reason to suspect that histochemical and histopathological features are not invariably related.

Mayeux et al. (1981) suggested that depression in parkinsonian patients may be accompanied by mild intellectual impairment and inattention which are independent of the severity of the illness. The pattern and degree of intellectual impairment did not warrant a diagnosis of dementia, particularly if criteria were strict. Dementia, they suggested, seems to affect older individuals with a more rapidly progressing Parkinson's disease that is likely to resist treatment. In contrast, patients with Parkinson's disease and depression were generally younger, and had a typically slow progression of the disease which usually responded to anticholinergic or dopaminergic therapy. Mayeux et al. (1981) concluded that there might be two types of intellectual impairment associated with Parkinson's disease. About $30 \%$ of their patients developed a global dementia, probably due to the coexistence of Alzheimer's disease and Parkinson's disease with cortical and subcortical pathology. Another $50 \%$ of patients may develop a mood disorder accompanied by impaired cognitive skills and inattention, but not a global dementia.

It must also be mentioned in this context - apropos of remarks made regarding the possible effects of treating depression in Alzheimer's disease - that the possibility of making Parkinson's disease patients more prone to dementia as a consequence of treating them and upsetting the relative cholinergic balance must be kept in mind.

\section{DEPRESSION ON DEMENTIA}

We must now consider the condition in which depression is superimposed on an underlying 'organic' dementia and aggravates the cognitive state. Shraberg (1978) questioned the concept of 'pseudodementia' after reporting a case in which depression cleared following treatment, revealing a patently organic dementia. McAllister \& Price (1982) and Rabins et al. (1984), among others, have shown that, even if the depression of a depressive 'pseudodementia' is removed by treatment, the dementia does not automatically recede. It is, in fact, a not uncommon observation that a full recovery from depression is not reflected in corresponding progress in the course of the dementia. Thus the superimposition of 'functional' psychiatric illness on an 'organic' degeneration is another possibility in states of dementia with depression. 


\section{DEPRESSION AND DEMENTIA COMMON TO BRAIN DYSFUNCTION}

We now have to turn our attention to those conditions which are infrequent examples of 'pseudodementia'. Some of these less common causes of 'pseudodementia' have already been mentioned. As depression was excluded from these diagnoses, one has presumably to seek a different mechanism. None is readily to hand, but one possible explanation may be that these conditions are due to brain dysfunction which produces these conditions on the one hand, and a cognitive disturbance amounting to dementia on the other. It is possible to postulate a spectrum of brain dysfunction with a reversible or benign dementia associated with clearly defined depressive features at one end and a malignant dementia with little or no depression at the other. Perhaps conditions like Parkinson's disease and Huntington's chorea with slower-progressing dementias and a substantial depressive component lie in between. It is also possible, in similar terms, to put forward the idea that an inverse relationship exists between depression and dementia. The more severe the dementia the less prominent or marked is the depression and vice versa. The neurobiological explanation for this phenomenon is lacking. The evidence in terms of differing cholinergic activity has been briefly discussed, but it is almost certain that evidence of a more complex nature will be forthcoming. The role of monoamines in depression and dementia, for example, is a complicated and confusing issue. To take one instance, serotonergic deficiency may be a feature of some depressive illness (Coppen \& Wood, 1982); serotonin activity may be unaltered in late onset, slower progressing Alzheimer's disease but its reduction may be a feature of the early onset, rapidly progressing form of the disease (Bowen et al. 1983). The complex relationship between the motor, affective and cognitive features of Parkinson's disease has already been alluded to and will perhaps serve as a model in unravelling the intricacies of neurobiology.

\section{A CRITIQUE OF THE CONCEPT OF 'PSEUDODEMENTIA'}

We must now turn to consider some of the assumptions that underlie the concept of 'pseudodementia'. It is not strictly true to claim that 'pseudodementia' of depressive or other causation does not produce 'organic' change. Obviously, reversible dementias due to such conditions as normal pressure hydrocephalus and space occupying lesions of the brain are associated with observable organic lesions. But, even with depression and other more obviously psychiatric conditions, where 'organic' features might be thought to be lacking or, at best, are subtle in their manifestations, there have been several reports of brain changes in the context of 'pseudodementia'. We have already noted that AEG, CT, EEG and psychometric evidence of brain damage exists in cases of 'pseudodementia', a fact which has always bedevilled the distinction between 'pseudo' and 'true' dementia made on the basis of physical investigations.

It must also be pointed out that, while anecdotal and single case reports suggest that it is the elderly who present with 'pseudodementia', the evidence from reported series of cases seems to suggest a wider range. Wells (1979) reported an age range between 33 and 69, and 7 of his 10 patients were in their fifties or sixties. Smith \& Kiloh (1981), reporting a series of 200 demented patients of all ages, showed that 'pseudodementia' accounted for $10 \%$ of all dementias under 45 years and for $13.6 \%$ of dementias between the ages of 45 and 64 years, but only for $1.8 \%$ of dementias over 65 years. McAllister's (1983) pooled series of cases yielded a mean of 60.5 years, with a range between 22 and 85 years. Marsden \& Harrison (1972), Nott \& Fleminger (1975) and Ron et al. (1979) all paid attention to pre-senile cases of dementia, with significant numbers of 'pseudodements'; Ron et al. (1979) commented that 'pseudodementia' was underemphasized in younger age groups (the latter two studies, indeed, sought to draw attention to the problems posed by 'pseudodementia' in the diagnosis of pre-senile dementia, circumstances which might have reflected the ease of case finding in this age-group). Thus, the prevalence of depressive 'pseudodementia' in relatively young patients, when by prediction it should have been found with increasing frequency in the patient in whom depression obtrudes upon the brain changes of ageing, needs to be explained. Also, while it is true, as Tomlinson et al. (1968) have shown, that structural brain changes in non-demented old people increase with age - in effect producing a closer approximation to Alzheimer-like pathology than in 
the younger subject - there is no difference between the changes in the brain between such non-dementing conditions as physical illness, confusional states, depressive illness and paraphrenia (Tomlinson et al. 1968; Roth, 1980). Thus, there is no especially susceptible brain available in the patient with depressive illness to lead beyond a threshold into dementia. The fact that depressive 'pseudodementia' occurs in middle age and not necessarily, or preferentially, in the senium when the age changes make the brain most vulnerable suggests that there is more to 'pseudodementia' than the fortuitous association between depressive illness and the ageing brain.

Furthermore, if depressive 'pseudodementia' were indeed induced simply by depression, it would be expected that the depressed affect would precede cognitive change and that there might be a time interval between the onset of depression and the onset of dementia. However, this does not seem to occur invariably. Clinical experience bears out that the depression and dementia often have a simultaneous onset. The lack of consistent temporal relationship between affective and cognitive change is matched by an inconsistent quantitative relationship. Very often, memory difficulties are seen to be as prominent as, if not greater than, the depressive features. McAllister \& Price (1982) noted a profound degree of cognitive impairment which appeared to be greatly out of proportion to the degree of depressive symptoms. They go on to say that: 'Referral had been for further evaluation and management of a presumed irreversible dementing illness and a diagnosis of depression and/or depressive pseudodementia had not been considered.' In fact, with the modern management of depressive illness, it is unlikely that depression will be allowed to reach a late stage at which dementia emerges. Progression of depression is towards increasing psychomotor retardation through semi-stupor to stupor, which are circumstances of altering consciousness in which the diagnosis of dementia becomes untenable. The evidence from recent literature, on the other hand, is that, if anything, 'pseudodementia', perhaps because of our awareness of the condition, is being reported more frequently, the prompt modern-day treatment of depression notwithstanding.

This body of evidence must throw considerable doubt on any simple notion of depressive 'pseudodementia' arising out of a depressive illness in an elderly patient, giving rise to cognitive change which progresses to dementia, which may then be reversed when the depression is successfully treated. The facts suggest that, in at least some cases, there is unlikely to be a fortuitous association between depressive illness and a brain with no other complicating factor than the vulnerability wrought by the changes of age. The wide ranges of the ages of the patients concerned, the mode of onset and presentation, the suspicion of predisposing brain lesions, the evidence of a greater degree of structural and functional brain impairment than would be expected with depressive or other 'functional' illness alone, and the often independent course of the dementia and depression suggest that some cases of 'pseudodementia' at least may deserve consideration as a discrete entity.

We have already noted the evidence for the affinity of depressive 'pseudodementia' with the dementias of Parkinson's disease, Huntington's chorea and the slower progressing, senile forms of Alzheimer's disease. It could be that all these forms reflect a common primary pathology in subcortical brain structures. The spectrum of brain dysfunction postulated in a previous paragraph may then accommodate some forms at least of 'pseudodementia' as depression and dementia, reflecting a relatively benign, and often reversible, brain dysfunction.

\section{CONCLUSION}

The relationship between depression and dementia is complex. We have seen how depression may produce cognitive changes which may reverse with the successful treatment of the depression, even leading to a full resolution of the dementia. A dementing illness may induce depression of a fleeting and ill-defined nature as with Alzheimer's disease, or induce a substantial component of the syndrome associated with Parkinson's disease and Huntington's chorea. A depressive illness, like any other condition, may be superimposed on and aggravate the cognitive state due to a chronic, degenerative condition giving rise to a dementia. And the possibility exists, as has been argued, that dementia and depression may be two limbs of a brain dysfunction which may be reversible to a greater or lesser degree. All that can be said with certainty in the present state of knowledge is that a clinician confronted with depression and dementia in a patient is fully entitled to accept this 
as a considerable challenge to his clinical prowess, to strive to dispel investigatory and therapeutic nihilism and, above all, to be conscious of changing concepts which are the logical outcome of advancing knowledge regarding both depression and dementia.

\section{B. MAHENDRA}

I should like to thank Dr Felix Post, Emeritus Physician, Bethlem Royal and Maudsley Hospital, for a most useful discussion of some aspects of this problem.

\section{REFERENCES}

Albert, M. L. (1978). Subcortical dementia. In Alzheimer's Disease: Senile Dementia and Related Disorders(ed. R. Katzman, R. D. Terry and K. L. Bick), pp. 173-180. Raven Press: New York.

Albert, M. L., Feldman, R. G. \& Willis, A. L. (1974). The subcortical dementia of progressive supranuclear palsy. Journal of Neurology, Neurosurgery and Psychiatry 38, 121-130.

Bowen, D. M., Allen, S. J., Benton, J. S., Goodhardt, M. J., Haan, E. A., Palmer, A. M., Sims, N. R., Smith, C. C. T., Spillane, J. A., Esiri, M. M., Neary, D., Snowdon, J. S., Wilcock, G. K. \& Davison, A. N. (1983). Biochemical assessment of serotonergic and cholinergic dysfunction and cerebral atrophy in Alzheimer's disease. Journal of Neurochemistry 41, 266-272.

Caine, E. D. (1981). Pseudodementia. Archives of General Psychiatry 38, $1359-1364$.

Carroll, B. J., Curtis, G. C. \& Mendels, J. (1976). Neuroendocrine regulation in depression: Il. Discrimination of depressed from non-depressed patients. Archives of General Psychiatry 33, 1051-1058.

Carroll, B. J., Greden, J. F., Rubin, R. T., Haskett, R., Feinberg, M. \& Schteingart, D. (1978). Neurotransmitter mechanism of neuroendocrine disturbance in depression. Acta Endocrinologica 220, Suppl., 14

Carroll, B. J., Feinberg, M., Greden, J. F., Tarika, J., Albala, A. A., Haskett, R. F., James, N. Mcl., Kronfol, Z., Lohr, N., Steiner, M., Devigne, J. P. \& Young, E. (1981). A specific laboratory test for the diagnosis of melancholia. Archives of General Psychiatry 38, 15-22.

Celesia, G. C. \& Wanamaker, W. M. (1972). Psychiatric disturbances in Parkinson's disease. Diseases of the Nervous System 33, 577-583.

Coppen, A. \& Wood, K. (1982). 5-Hydroxytryptamine in the pathogenesis of affective disorders. Serotonin in Biological Psychiatry (ed. B. T. Ho, J. C. Schoolar and E. Usdin), pp. 13-34. Raven Press: New York.

Gaupp, R. (1905). Die Depressionszustaende des hoeheren Lebensalters. Muenchener Medizinische Wochenschrift 52, 1531 (quoted by Post, 1962).

Gibson, A. J. (1981). A further analysis of memory loss in dementia and depression in the elderly. British Journal of Clinical Psychology $20,179-185$.

Jacoby, R. (1981). Dementia, depression and the CT scan. Psychological Medicine 11, 673-676.

Jacoby, R., Dolan, R. J., Levy, R. \& Baldy, R. (1983). Quantitative computed tomography in elderly depressed patients. British Journal of Psychiatry 143, 124-127.

Kiloh, L. G. (1961). Pseudo-dementia. Acta Psychiatrica Scandinavica 37, 336-351.

Knesevich, J. W., Martin, R. L., Berg, L. \& Danziger, W. (1983). Preliminary report of affective symptoms in the early stages of senile dementia of the Alzheimer type. American Journal of Psychiatry $140,233-235$

Kral, V.A. (1983). The relationship between senile dementia (Alzheimer type) and depression. Canadian Journal of Psychiatry 28, $304-306$.

Lange, J. (1928). Die endogenen und reaktiven Gemuetserkrankungen. In Handbuch der Geisteskrankheiten Vol. 2 (ed. O. Bumke), p. 4 (quoted by Post, 1962).

Lishman, W. A. (1978). Organic Psychiatry. Blackwell Scientific: Oxford.
McAllister, T. W. (1983). Pseudodementia. American Journal of Psychiatry 140, 528-533.

McAllister, T. W. \& Price, T. R. P. (1982). Severe depressive pseudodementia with and without dementia. American Journal of Psychiatry 139, 626-629.

Madden, J. J., Luhan, J. A., Kaplan, L. A. \& Manfredi, H. M. (1952). Nondementing psychoses in older persons. Journal of the American Medical Association 150, 1567-1570.

Mahendra, B. (1983). 'Pseudodementia ': an illogical and misleading concept. British Journal of Psychiatry 143, 202

Mahendra, B. (1984). Dementia and the abnormal Dexamethasone Suppression Test. British Journal of Psychiatry 144, 98-99.

Marsden, C. D. (1982). Basal ganglia disease. Lancet ii, 1141-1147.

Marsden, C. D. \& Harrison, M. J. G. (1972). Outcome of investigation of patients with presenile dementia. British Medical Journal ii, 249-252.

Mayer Gross, W., Slater, E. \& Roth, M. (eds.) (1960). Clinical Psychiatry (7th edn). Cassell: London.

Mayeux, R., Stern, Y., Rosen, J. \& Leventhal, J. (1981). Depression, intellectual impairment and Parkinson's disease. Neurology 31, 645-650.

Mayeux, R., Stern, Y., Rosen, J. \& Benson, D. F. (1983). Is 'subcortical dementia' a recognizable clinical entity? Annals of Neurology 14, 278-283.

Mindham, R. H. S. (1970). Psychiatric symptoms in Parkinsonism. Journal of Neurology, Neurosurgery and Psychiatry 33, 188-191.

Mindham, R. H. S., Ahmed, S. W. A. \& Clough, C. G. (1982). A controlled study of dementia in Parkinson's disease. Journal of Neurology, Neurosurgery and Psychiatry 45, 969-974.

Nott, P. N. \& Fleminger, J. J. (1975). Presenile dementia: the difficulties of early diagnosis. Acta Psychiatrica Scandinavica 51, 210-217.

Perry, R. H., Tomlinson, B. E., Candy, J. M., Blessed, G., Foster, J. F., Bloxham, C. A. \& Perry, E. K. (1983). Cortical cholinergic deficit in mentally impaired Parkinsonian patients. Lancet ii, 789-790.

Post, F. (1962). The Significance of Affective Symptoms in Old Age. Oxford University Press: London.

Rabins, P. V., Merchant, A. \& Nestadt, G. (1984). Criteria for diagnosing reversible dementia caused by depression. British Journal of Psychiatry 144, 488-492.

Robins, A. H. (1976). Depression in patients with Parkinsonism. British Journal of Psychiatry 128, 141-145.

Ron, M. A., Toone, B. K., Garralda, M. E. \& Lishman, W. A. (1979). Diagnostic accuracy in presenile dementia. British Journal of Psychiatry 134, 161-168.

Rosen, G. (1961). Cross cultural and historical approaches. In Psychopathology of Ageing (ed. P. H. Hoch and J. Zubin), pp. 1-20. Grune and Stratton: New York.

Roth, M. (1978). Diagnosis of senile and related forms of dementia. In Alzheimer's Disease: Senile Dementia and Related Disorders (ed. R. Katzman, R. D. Terry and K. L. Bick), pp. 71-85. Raven Press: New York.

Roth, M. (1980). Senile dementia and its borderlands. In Psychopathology in the Aged (ed. J. O. Cole and J. E. Barrett), pp. 205-232. Raven Press: New York.

Royal College of Physicians (1981). Report: Organic mental impairment in the elderly. Journal of the Royal College of Physicians of London 15, 141-167.

Rudorfer, M. V. \& Clayton, P. J. (1981). Depression, dementia and 
dexamethasone suppression. American Journal of Psychiatry 138, 701.

Seltzer, B. \& Sherwin, I. (1983). A comparison of clinical features in early-and late-onset primary degenerative dementia. Archives of Neurology 40, 143-146.

Shraberg, D. (1978). The myth of pseudodementia; depression and the ageing brain. American Journal of Psychiatry 135, 601-603.

Smith, J. S. \& Kiloh, L. G. (1981). The investigation of dementia: results in 200 consecutive admissions. Lancet i, 824-827.

Sourander, P. \& Sjogren, H. (1970). The concept of Alzheimer's disease and its clinical implications. In Alzheimer's Disease and Related Conditions (ed. G. W. Wolstenholme and M. O'Connor), pp. 11-32. Churchill: London.
Spar, J. E. \& Gerner, R. (1982). Does the Dexamethasone Suppression Test distinguish dementia from depression? American Journal of Psychiatry 139, 238-240.

Tomlinson, B. E., Blessed, G. Roth, M. (1968). Observations on the brains of non-demented old people. Journal of Neurological Science 7, 331-356.

Weingartner, H., Cohen, R. M., Bunney, W. E., Ebert, M. H. \& Kaye, W. (1982). Memory - learning impairments in progressive dementia and depression. American Journal of Psychiairy 139. 135-136.

Wells, C. E. (1979). Pseudodementia. American Journal of Psychiatry 136, 895-900. 